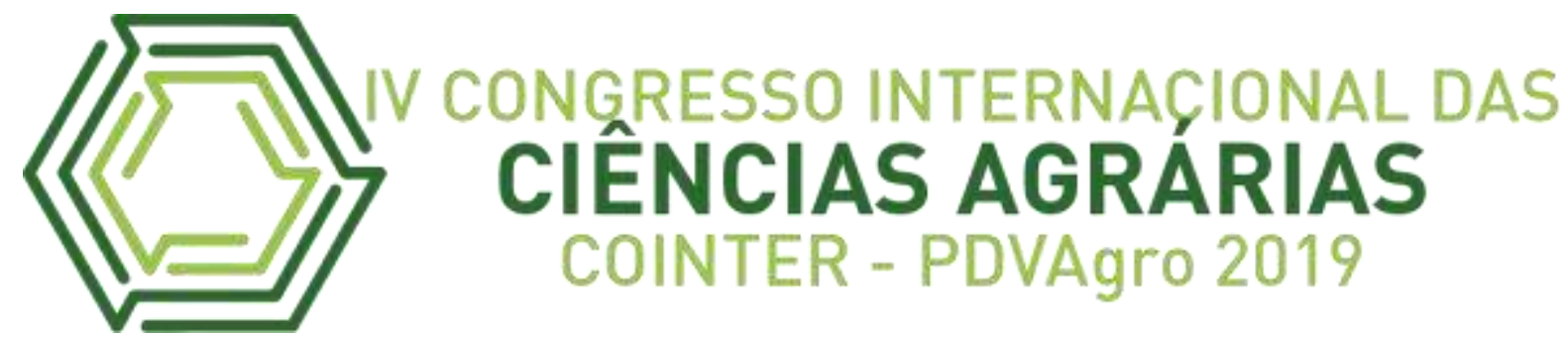

\title{
AVALIAÇÃO DA PRODUÇÃO DE FITOMASSA E SINTOMAS DE DEFICIÊNCIA NA CULTURA DO JAMBU [ Acmella oleracea (1.) R. K. Jansen] CULTIVADO SOB OMISSÃO DE MACRONUTRIENTES E FERRO
}

\author{
EVALUACIÓN DE LA PRODUCCIÓN DE FITOMASAS Y SÍNTOMAS DE \\ DEFICIENCIA EN LA CULTURA DE JAMBU [Acmella oleracea (1.) R. K. Jansen] \\ CULTIVADO BAJO MACRONUTRIENTE Y OMISIÓN DE HIERRO
}

\section{EVALUATION OF PHYTOMASS PRODUCTION AND SYMPTOMS OF DEFICIENCY IN JAMBU CULTURE [Acmella oleracea (l.) R. K. Jansen] CULTIVATED UNDER MACRONUTRIENT AND IRON OMISSION}

\author{
Apresentação: Comunicação Oral \\ Paulo Sergio da Costa Trindade ${ }^{1}$; Aurino Dias de Oliveira Filho ${ }^{2}$; Elidaiane de Sousa Farias ${ }^{3}$ \\ Pâmela Alves dos Santos ${ }^{4}$; Welliton de Lima Sena ${ }^{5}$
}

DOI: https://doi.org/10.31692/2526-7701.IVCOINTERPDVAgro.2019.0158

\section{Resumo}

O jambu [ Acmella oleracea (L.) R. K. Jansen] possui o Norte do Brasil como um de seus centros de origem. Esse vegetal é amplamente consumido na culinária regional, e vem ganhando espaço principalmente por suas propriedades medicinais. Devido esse maior interesse por suas qualidades biológicas ainda são poucos os estudos que tratam de seu manejo nutricional bem como as possíveis desordens geradas a partir da carência de um determinado nutriente. Objetivou-se com esse trabalho avaliar os efeitos da omissão de macronutrientes e ferro em plantas de jambu sob omissão de nutrientes, caracterizando os sintomas visuais de deficiência produzidos pelas plantas, avaliando dados de produção de massa seca aérea e radicular. $O$ experimento foi conduzido em casa de vegetação. $O$ delineamento estatístico foi inteiramente casualizado com oito tratamentos e cinco repetições. As plantas cresceram em solução completa contendo todos os nutrientes até o início do florescimento, e a partir desse momento, foram aplicados os tratamentos: Solução Completa, Omissão de Nitrogênio, Omissão de Fósforo, Omissão de Potássio, Omissão de Cálcio, Omissão de Magnésio, Omissão de Enxofre e Omissão de Ferro. Diariamente eram aplicadas as soluções e realizadas avaliações nas plantas buscando caracterizar os sintomas de deficiência. A coleta das plantas foi realizada 35 dias após o início dos tratamentos e foi

\footnotetext{
${ }^{1}$ Agronomia, IFPA, paulocostaoficiall@gmail.com

${ }^{2}$ Agronomia, IFPA, pc_aurino@hotmail.com

${ }^{3}$ Agronomia, IFPA, daianesfariass@gmail.com

${ }^{4}$ Agronomia, IFPA, pamelaalves1530@gmail.com

${ }^{5}$ Professor Doutor, IFPA, welliton.sena@ifpa.edu.br
} 
avaliada matéria seca da parte aérea e das raízes, bem como a descrição dos sintomas observados durante a condução do experimento. No momento da coleta realizou a separação do material em parte aérea e radicular, os materiais foram identificados, acondicionados em saco de papel Kraft e encaminhados ao laboratório de solos do IFPA, o material foi seco em estufa a $65^{\circ} \mathrm{C}$ por $72 \mathrm{~h}$, até atingir massa constante. Ao retirar o material da estufa, foi realizada a pesagem em balança digital. Após isso foi realizado a tabulação dos dados e utilizado o programa estatístico IBM SPSS para realizar as análises estatísticas. A omissão permitiu a visualização dos sintomas de deficiência. Com isso foi possível verificar a limitação ao crescimento das plantas com o agravamento dos sintomas, principalmente no tratamento com omissão de potássio, que foi o tratamento mais limitante ao crescimento da cultura. Em ordem decrescente os tratamentos que mais limitaram o crescimento da cultura forma: Potássio $>$ Nitrogênio $>$ Cálcio $>$ Fósforo $>$ Magnésio $>$ Enxofre $>$ Ferro. Portanto, a omissão de nutrientes confere uma importante ferramenta na visualização das deficiências nutricionais.

Palavras-Chave: Omissão, Nutrição, Jambu.

\section{Resumen}

El jambu [ Acmella oleracea (L) R. K. Jansen] posee el Norte del Brasil como uno de sus centros centros del origen. Ese vegetal es ampliamente consumido en la culinaria regional, y viene ganando espacio principalmente por sus propiedades medicinales. Debido ese mayor interés por sus cualidades biológicas aún son pocos los estudios que tratan de su manejo nutricional bien como las posibles desórdenes generadas de la carencia de un determinado nutriente. Se objetiva con este trabajo evaluar los efectos de la omisión de macronutrientes y fierro en plantas de jambu sob omisión de nutrientes, caracterizando los síntomas visuales de deficiencia produzidos por las plantas, evaluando datos de producción de masa seca aérea y radicular. El experimento fue conducido en casa de vegetación. El delinear estatístico fue inteiramente casualizado en ocho tratamientos y cinco repeticiones. Las plantas crecieron en solución completa conteniendo todos los nutrientes hasta el inicio del florecimiento, y a partir de entonces, fueron aplicados los tratamientos: Solución Completa, Omisión de Nitrógeno, Omisión de Fósforo, Omisión de Potasio, Omisión de Calcio, Omisión de Magnesio, Omisión de Enxofre y Omisión de Fierro. Diariamente, eran aplicadas las soluciones y eran realizadas las evaluaciones en las plantas proponiendose a caracterizar los síntomas de deficiencia. La coleta de las plantas fue hecha treinta y cinco días tras el inicio del tratamiento y fue evaluada la materia seca de la parte aérea y de las raíces, bien como la descripción de los síntomas observados durante la conducción del experimento. En el momento de la coleta fuera hecha la separación del material en parte aérea y radicular, los materiales fueron identificados, acondicionas en bolsos de papel Kraft y direccionados al laboratorio de suelos del IFPA, el material fue secado en invernadero a sesenta y cinco grados por setenta y dos horas, hasta atingir masa constante. Al sacar el material del invernadero, fue hecha el pesaje en balanza digital. después de eso, fue hecha la tabulación de los datos y utilizado el programa estadístico IBM SPSS para realizar los análisis estadísticas. La omisión permitió la visualización de los síntomas de deficiencia. Con eso, fuera posible verificar la limitación al crecimiento de las plantas con el desarrollo de los síntomas, principalmente en el tratamiento con omisión de potasio, que fue el tratamiento más limitante al crecimiento de la cultura. En orden decreciente los tratamientos que más limitan el crecimiento de la cultura muestra: Potasio> 
Nitrógeno> Calcio>Fósforo> Magnesio> Enxofre> Fierro. Así, la omisión de nutrientes confiere una importante herramienta para la visualización de las deficiencias nutricionales.

Palabras Clave: Omisión, Nutrición, Jambu

\begin{abstract}
The jambu [Acmella oleracea (L.) R. K. Jansen] has northern Brazil as one of its centers of origin. This vegetable is widely consumed in regional cuisine, and has been gaining ground mainly for its medicinal properties. In spite of the big interest for its biological qualities, there are few studies that deal with its nutritional management as well as the possible disorders generated from the lack of a particular nutrient. The aim of this study was to evaluate the effects of macronutrient and iron omission on nutrient omission of jambu plants, characterizing the visual deficiency symptoms produced by the plants, evaluating air and root dry mass production data. The experiment was conducted in a greenhouse. The statistical design was completely randomized with eight treatments and five repetitions. The plants were grown in complete solution containing all the nutrients until the beginning of flowering, and from that moment, the treatments were applied: Complete Solution, Nitrogen Omission, Phosphorus Omission, Potassium Omission, Calcium Omission, Magnesium Omission, Sulfur omission and iron omission. Solutions were applied daily and plant evaluations were performed to characterize the deficiency symptoms. The plants were collected 35 days after the beginning of the treatments and the shoot and root dry matter were evaluated, as well as the description of the symptoms observed during the experiment. At the time of collection, the material was separated into aerial and root parts, the materials were identified, placed in a Kraft paper bag and sent to the IFPA soil laboratory. The material was oven dried at $65 \mathrm{C}$ for 72 hours until it reached a constant mass. When removing the material from the kiln, digital scale weighing was performed. After that the data were tabulated and the statistical software IBM SPSS was used to perform the statistical analyzes. The omission allowed the visualization of symptoms of deficiency. With this it was possible to verify the limitation to plant growth with the worsening of symptoms, especially in the treatment with potassium omission, which was the most limiting treatment to the growth of the crop. In decreasing order the treatments that most limited the growth of the culture were: Potassium> Nitrogen> Calcium> Phosphorus > Magnesium > Sulfur > Iron. Therefore, nutrient omission provides an important tool for visualizing nutritional deficiencies.
\end{abstract}

Keywords: Omission, Nutrition,Jambu

\title{
Introdução
}

Típico da Região Norte do Brasil, o jambu [ Acmella oleracea (L.) R. K. Jansen], é caracterizado como uma hortaliça herbácea, semiereta ou quase rastejante, com caule cilíndrico, carnoso e de ramos decumbentes, pertencente à família Asteraceae (GUSMÃO \& GUSMÃO, 2013). Considerado uma hortaliça folhosa, o jambu tem conquistado inúmeros consumidores por apresentar propriedades peculiares, sendo a mais importante à sensação 
anestésica momentânea, ocasionada pelo consumo de suas partes vegetativas (HOMMA et al., 2014).

Devido a essa propriedade, o jambu alcançou lugar de destaque na culinária do Brasil, além de ser considerado uma erva medicinal pela população ribeirinha, que utiliza seus preparados para o tratamento de dor de dente e moléstias da garganta (RODRIGUES et al., 2014). A sensação anestésica deve-se à presença do espilantol (BARBOSA et al. , 2016), um composto bioativo do grupo químico das alquilamidas com diversas propriedades farmacológicas. Tal substância tem sido estudada pela indústria de fármacos e de cosméticos, sendo usada como constituinte de cremes para combate a expressões de idade e de pomadas que substituem a anestesia em processos odontológicos (HOMMA et al., 2014; BARBOSA et al., 2016). Estudos recentes têm comprovado que o jambu, devido à presença do espilantol, pode apresentar diversas propriedades farmacológicas, como capacidade anti-inflamatória, analgésica, antioxidante, antipirética, inseticida, diurética e afrodisíaca (DUBEY et al., 2013; PRACHAYASITTIKUL et al., 2013; BARBOSA et al., 2016).

Devido ao maior interesse pela atividade biológica dessa planta, a maioria dos estudos é voltada para este aspecto. Poucos são os estudos que buscam o manejo nutricional e as possíveis desordens ocasionadas pelas alterações no fornecimento nutricional ao jambu (ALVES PEÇANHA, 2019). Nota-se ainda a ausência de estudos que estabeleçam uma relação entre alguns parâmetros de qualidade do vegetal e a resposta quanto à omissão de nutrientes minerais.

Segundo Malavolta (1980), as desordens nutricionais, deficiências, excesso e desequilíbrio causam diminuição no desenvolvimento e na produção de qualquer cultura. Tal diminuição é, em geral, precedida por sintomas visuais, geralmente mais evidentes nas folhas, embora a produtividade e a produção possam já estar comprometidas, mesmo antes da manifestação dos sintomas. Por meio da diagnose visual, é possível caracterizar sintomas de deficiência que, geralmente, são mais visíveis nas folhas. Para se caracterizar essas deficiências com mais segurança e sem a interação com outros fatores, o cultivo em solução nutritiva é uma opção viável, permitindo associar os sintomas visíveis com a composição mineral do tecido vegetal (BARROSO et al. 2005).

Objetivou-se com esse trabalho avaliar os efeitos da omissão de macronutrientes e ferro $(\mathrm{Fe})$ em plantas de jambu, caracterizando os sintomas visuais produzidos pelas plantas, avaliando dados de produção de massa seca aérea e radicular. 


\section{Fundamentação Teórica}

A análise nutricional é responsável por identificar quais elementos são essenciais para o ciclo de vida da planta, de que maneira tais elementos são absorvidos, translocados e acumulados, suas funções, as exigências e os distúrbios que causam quando são fornecidas em quantidades deficientes ou excessivas (SOUZA, 2017). Segundo Malavolta (1980) as exigências nutricionais são avaliadas de maneira qualitativas e quantitativas.

Uma maneira rápida e econômica de se conhecer as exigências nutricionais de uma espécie é por meio da técnica do elemento faltante. Essa técnica envolve o crescimento de uma planta sob condições de campo ou casa de vegetação, em que é testado um tratamento completo (com todos os nutrientes necessários em doses adequadas) e uma série de tratamentos, nos quais é feita a omissão de um nutriente de cada vez. Normalmente, considera-se como deficiência severa quando a produção de massa seca cai a $40 \%$ em relação ao tratamento completo (SANCHES, 1981). Empregando-se a técnica do elemento faltante, podem-se verificar quais os nutrientes que se apresentam deficientes, a importância relativa dessa deficiência e a taxa de redução da fertilidade do solo quando se utilizam plantas que permitem cortes sucessivos (CHAMINADE, 1972). Segundo Malavolta (1980), ela representa uma referência semiquantitativa da necessidade de adubação. Vários trabalhos vêm sendo realizados com diferentes espécies utilizando-se essa técnica (SILVA et al., 2005, 2007; VENTURIN et al., 2005; SOUZA et al., 2006;).

Os nutrientes minerais são um dos muitos fatores que podem influenciar no crescimento e desenvolvimento do vegetal, bem como água, radiação e temperatura. $\mathrm{O}$ manejo adequado dos nutrientes é um fator chave no cultivo de qualquer vegetal a fim de se maximizar seu objetivo final, seja ele massa fresca, teor de sólidos solúveis, pegamento de frutos ou teor de óleos essenciais, entre muitos outros. Cada nutriente mineral presente nas plantas possui funções características. Hawkesford et al. (2012), classificam 14 elementos químicos como nutrientes minerais essenciais, dividindo-os em dois grandes grupos: macro e micronutrientes, baseando-se nos teores requeridos pelos vegetais. Os macronutrientes são nitrogênio, fósforo, potássio, cálcio, magnésio e enxofre. Os 8 micronutrientes são ferro, zinco, manganês, cobre, cloro, boro, molibdênio e níquel.

Ao atender os critérios de essencialidade, seja como parte estrutural de algum composto ou envolvido em alguma rota metabólica de forma insubstituível, o nutriente torna- 
se peça chave para o desenvolvimento das plantas. Quando acontece a ausência de algum deles, o desenvolvimento normal do vegetal é prejudicado (EPSTEIN E BLOOM, 2004). As anormalidades oriundas do desbalanço nutricional podem ocorrer a nível celular, culminando em alterações visuais nos vegetais. A caracterização dos sintomas visuais provocados pela deficiência nutricional é uma importante ferramenta de diagnóstico, aliada à análise foliar (CARMONA et al., 2015). No caso específico do jambu, nota-se a ausência de estudos que estabeleçam uma relação entre a qualidade da planta e o fornecimento de nutrientes minerais. A busca por doses nutricionais ideais que visem uma boa produção de biomassa e Inflorescências necessita de estudos complementares para melhor entendimento dos fatores abióticos que podem influenciar na produção da planta (RODRIGUES et al., 2014).

\section{Metodologia}

A pesquisa é de natureza quantitativa e o experimento foi realizado em casa de

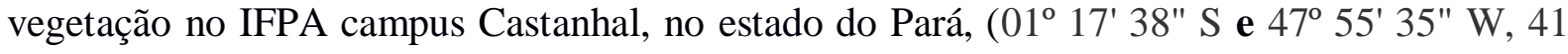
metros de altitude), no período de maio a julho de 2019. O delineamento utilizado foi inteiramente casualizado, com oito tratamentos e cinco repetições. Cada unidade experimental foi composta por um vaso de 6L. Os tratamentos foram baseados na Solução de Hoagland e Arnon (1950) de acordo com Tabela 1 com variações para cada omissão de interesse: Solução Completa (com todos os nutrientes) (SC), Omissão de Nitrogênio (-N), omissão de Fósforo (P), omissão de Potássio (-K), omissão de Cálcio (-Ca), omissão de Magnésio (-Mg), omissão de Enxofre (-S) e omissão de Ferro (-Fe).

Tabela 1 - Soluções estoque utilizadas no preparo das soluções nutritivas completa e deficientes em N, P, K, Ca, $\mathrm{Mg}, \mathrm{S}$, utilizadas no experimento. * A solução de micronutrientes tem a seguinte composição em $\mathrm{g} \mathrm{L}^{-1}: \mathrm{H}_{3} \mathrm{BO}_{3}$, 2,$86 ; \mathrm{MnCl}_{2} \cdot 4 \mathrm{H}_{2} \mathrm{O}, 1,81 ; \mathrm{ZnCl}_{2}, 010 ; \mathrm{CuCl}_{2}, 0,0_{4} ; \mathrm{H}_{2} \mathrm{MoO}_{4} \cdot \mathrm{H}_{2} \mathrm{O}, 0,02$.

\begin{tabular}{|c|c|c|c|c|c|c|c|}
\hline \multirow{2}{*}{ Solução estoque } & \multicolumn{7}{|c|}{ Tratamentos $\left(\mathrm{mL} \mathrm{L} \mathbf{L}^{-1}\right)$} \\
\hline & Completo & $-\mathbf{N}$ & $-\mathbf{P}$ & $-K$ & $-\mathbf{C a}$ & $-\mathrm{Mg}$ & $-S$ \\
\hline $\mathrm{KNO}_{3} \mathrm{~mol} \mathrm{~L}^{-1}$ & 5 & - & 6 & - & 5 & 6 & 6 \\
\hline $\mathrm{Ca}\left(\mathrm{NO}_{3}\right)_{2} \cdot 4 \mathrm{H}_{2} \mathrm{O} \mathrm{mol} \mathrm{L}^{-1}$ & 5 & - & 4 & 5 & - & 4 & 4 \\
\hline $\mathrm{MgSO}_{4} \cdot 7 \mathrm{H}_{2} \mathrm{~mol} \mathrm{~L}^{-1}$ & 2 & 2 & 2 & 2 & 2 & - & - \\
\hline $\mathrm{CaSO}_{4} 0,01 \mathrm{~mol} \mathrm{~L}^{-1}$ & - & 200 & - & - & - & - & - \\
\hline $\mathrm{Ca}\left(\mathrm{H}_{2} \mathrm{PO}_{4}\right)_{2} \quad 0,05 \mathrm{~mol} \mathrm{~L}^{-1}$ & - & 10 & - & 10 & - & - & - \\
\hline $\mathrm{Mg}\left(\mathrm{NO}_{3}\right)_{2} \cdot 6 \mathrm{H}_{2} \mathrm{O}$ & - & - & - & - & - & - & 2 \\
\hline
\end{tabular}




\begin{tabular}{llllllll} 
Micronutrientes & 1 & 1 & 1 & 1 & 1 & 1 & 1 \\
Fe - EDTA & 1 & 1 & 1 & 1 & 1 & 1 & 1 \\
$\mathrm{KH}_{2} \mathrm{PO}_{4}\left(1 \mathrm{~mol} \mathrm{~L}^{-1}\right)$ & 1 & - & - & - & 1 & 1 & 1 \\
$\mathrm{~K}_{2} \mathrm{SO}_{4}\left(0,5 \mathrm{~mol} \mathrm{~L}^{-1}\right)$ & - & 5 & - & - & - & 3 & - \\
\hline
\end{tabular}

Fonte: Hoagland e Arnon (1950)

Após o sorteio das parcelas, foi realizada a confecção do croqui do experimento de acordo com a tabela 2. Utilizou-se como substrato areia lavada em solução com água, saturando a areia nos vasos. Foram utilizadas mudas produzidas em bandejas de 128 células, utilizando areia como substrato. Quando as plantas estavam com aproximadamente 10 dias foi realizado o transplantio para os vasos contendo areia lavada, ficando duas plantas por vasos, e dado início a aplicação da solução completa sendo aplicada diariamente, até que as plantas chegassem ao início do florescimento. Ao apresentarem as inflorescências iniciou-se a aplicação das soluções dos tratamentos com as omissões, diariamente. Previamente, no laboratório de solos do IFPA, foi realizada a produção das soluções estoques, e a partir dessas soluções foram realizadas as diluições para produzir as soluções de omissão de nutrientes.

Tabela 2 - Croque das Parcelas após o sorteio

\begin{tabular}{|c|c|c|c|c|c|c|c|c|c|}
\hline NR3 & MR5 & PR1 & TR1 & SR3 & MR2 & MR3 & SR4 & TR4 & CR4 \\
\hline PR2 & KR5 & SR2 & KR4 & FR1 & KR3 & NR5 & CR3 & KR2 & FR3 \\
\hline SR1 & TR5 & FR5 & PR3 & PR4 & FR2 & FR4 & PR5 & CR5 & NR4 \\
\hline NR1 & MR4 & NR2 & CR1 & TR2 & MR1 & SR5 & TR3 & CR2 & KR1 \\
\hline
\end{tabular}

Fonte: Autores (2019)

Durante a condução do experimento, o desenvolvimento das plantas foi acompanhado e foram registrados por fotografia todos os sintomas ocorridos. As plantas foram coletadas 35 dias após o início dos tratamentos e foi avaliada a matéria seca da parte aérea e das raízes, bem como a descrição dos sintomas de deficiência. No momento da coleta realizou-se a separação do material vegetal em parte aérea e raízes, os materiais foram identificados, acondicionados em saco de papel Kraft e encaminhados ao laboratório de solos do IFPA, o material foi seco em estufa a $65^{\circ} \mathrm{C}$ por $72 \mathrm{~h}$, até atingir massa constante. Ao retirar o material da estufa, foi realizada a pesagem em balança digital. Após isso foi realizado a tabulação dos 
dados e utilizado o programa estatístico IBM SPSS para realizar as análises estatísticas. Foram realizadas análises de variância e teste de Tukey a nível 5 \% de significância.

\section{Resultados e Discussão}

Descrição dos Sintomas de Deficiência

Os primeiros sintomas de deficiência observados foram de potássio, mostrando-se um nutriente muito limitante para a cultura do Jambu apresentando sintoma de clorose ao longo dos bordos das folhas mais velhas como apresentada na figura 1 aumentando gradativamente dos bordos para o ápice da folha. Isso é explicado pelo fato do potássio ser um elemento bastante móvel no floema, sendo redistribuído para regiões em franco crescimento da planta (FERNANDES, 2006; YOST et al., 2011).

Sintomas semelhantes foram observados por Viegas (2008) ao analisar o efeito da omissão de nutrientes na cultura do açaí. Com o agravamento dos sintomas, as folhas do jambu apresentaram necrose geral nas folhas mais velhas. Resultados encontrados por Prado \& Leal (2006) corroboram com os resultados encontrados no presente trabalho, ao submeter o girassol à deficiência de potássio observou resultados semelhantes, onde a deficiência favoreceu o surgimento de clorose nas folhas baixeiras, especialmente nas bordas e pontas das folhas.

Figura 1- Vaso a esquerda da imagem com Solução Completa; vaso à direita omissão de potássio (K)

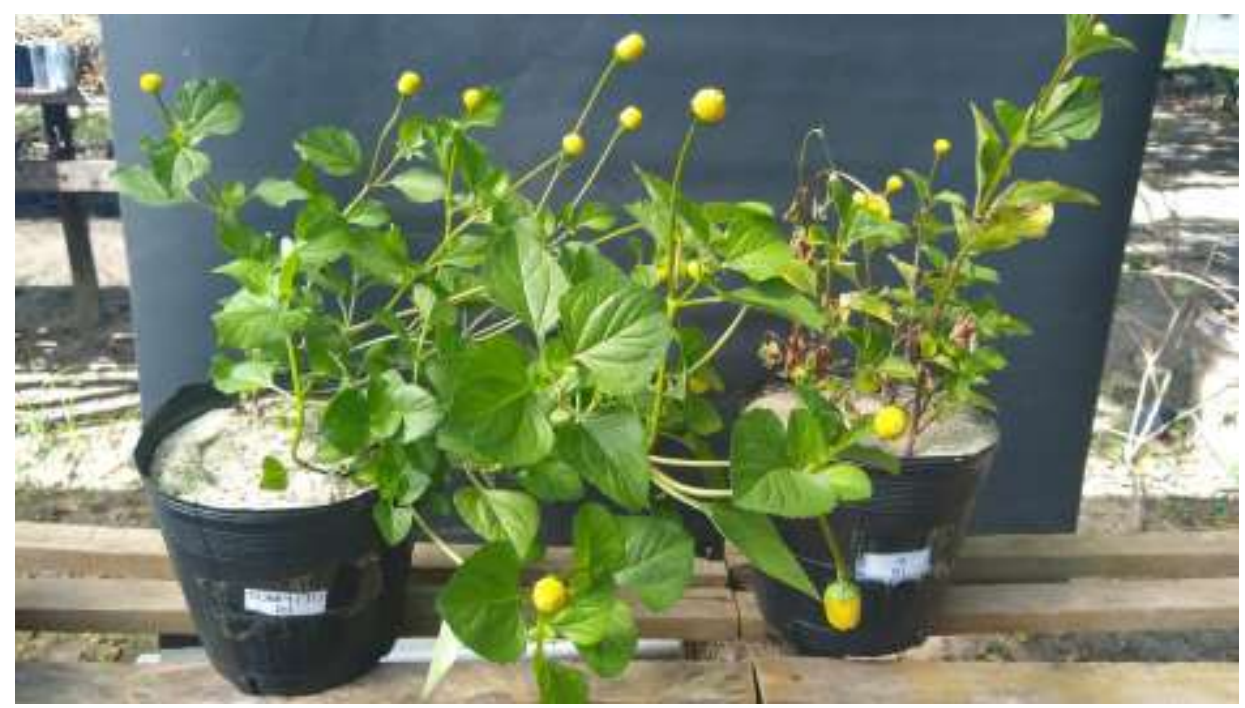


Fonte: Autores (2019)

Na omissão do nitrogênio foi verificada inicialmente coloração verde clara nas folhas mais velhas como mostra a figura 2, avançando para um quadro de amarelecimento total das folhas, caracterizando-se como um nutriente limitante ao crescimento para a cultura. Essa característica faz com que planta apresentante alta demanda por esse nutriente, sendo necessário em altas quantidades para os pontos de crescimento, com isso o metabolismo pode realocar o nitrogênio das zonas mais próximas para atender a demanda nutricional da cultura. (TAIZ E ZEIGER, 2013). Alguns sintomas de amarelecimento foram observados por Haag et al (1971) quando realizou omissão de nutrientes com esse elemento. Segundo Malavolta et al. (1997) este sintoma está relacionado com a diminuição da produção de clorofila, levando a uma modificação dos cloroplastos. Foram observados também folhas pequenas e plantas de pequeno porte, isso é ocasionado pelo valor relevante que o nitrogênio tem na divisão celular (MENDES, 1959) levando a uma diminuição de crescimento da planta.

Figura 2 - Vaso a esquerda da imagem com Solução Completa; vaso à direita omissão de Nitrogênio (N)

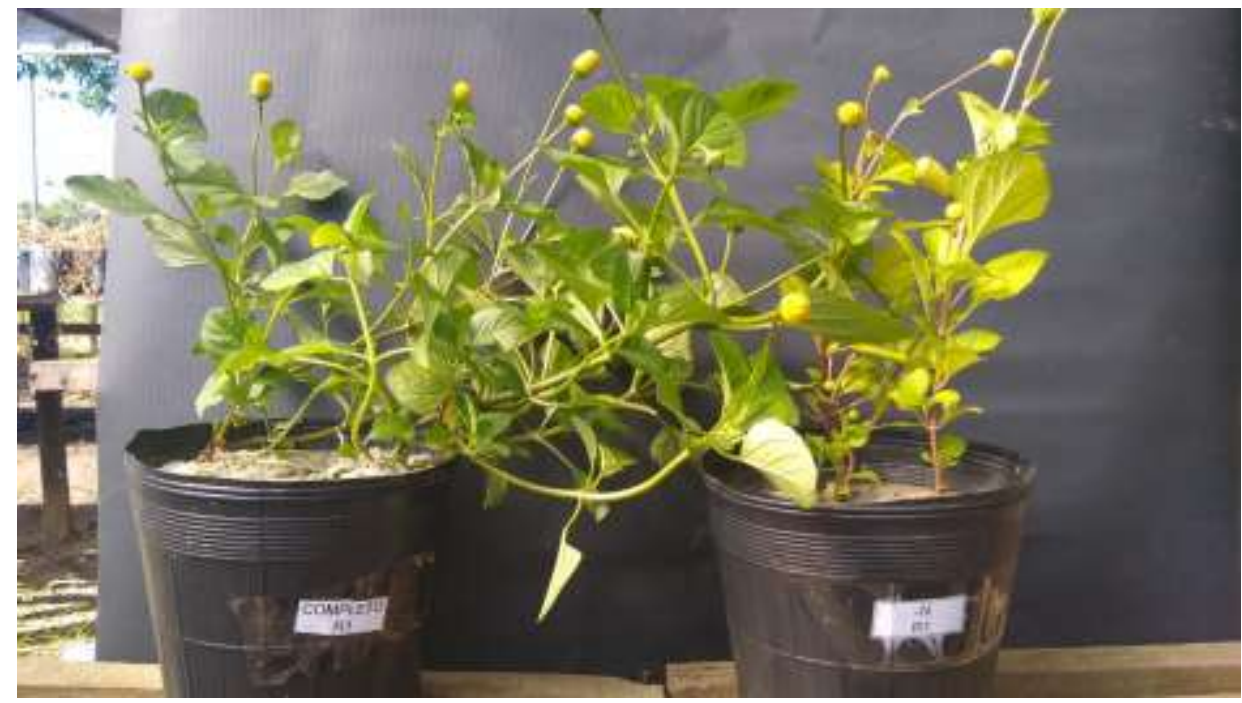

Fonte: Própria (2019)

$\mathrm{Na}$ omissão de fósforo, os sintomas de deficiência foram clorose nas folhas mais velhas, como podemos visualizar na figura 3, pois esse nutriente é altamente móvel com relação a sua redistribuição para novos tecido em formação na planta. Sintomas semelhantes foram encontrados por Silva (2013) quando observou sintomas de clorose na cultura do pimentão. Foram observadas folhas pequenas, retardo no crescimento inicia de coloração púrpura nas folhas mais velhas. De acordo Taizz e Zeiger (2013), assim como pode ocorrer na 
deficiência de nitrogênio, algumas espécies sob deficiência de P podem produzir antocianinas em excesso, conferindo às folhas coloração levemente arroxeada ou verde escura. Além disso, foi observado redução do porte da planta quando comparada ao tratamento completo, Segundo Malavolta (1985) o fósforo é essencial na divisão celular, e sua deficiência causa menos formação de raízes, redução na frutificação e no teor de carboidratos, óleos e proteínas.

Figura 3 - Vaso a esquerda da imagem com Solução Completa; vaso à direita omissão de Fósforo (P)

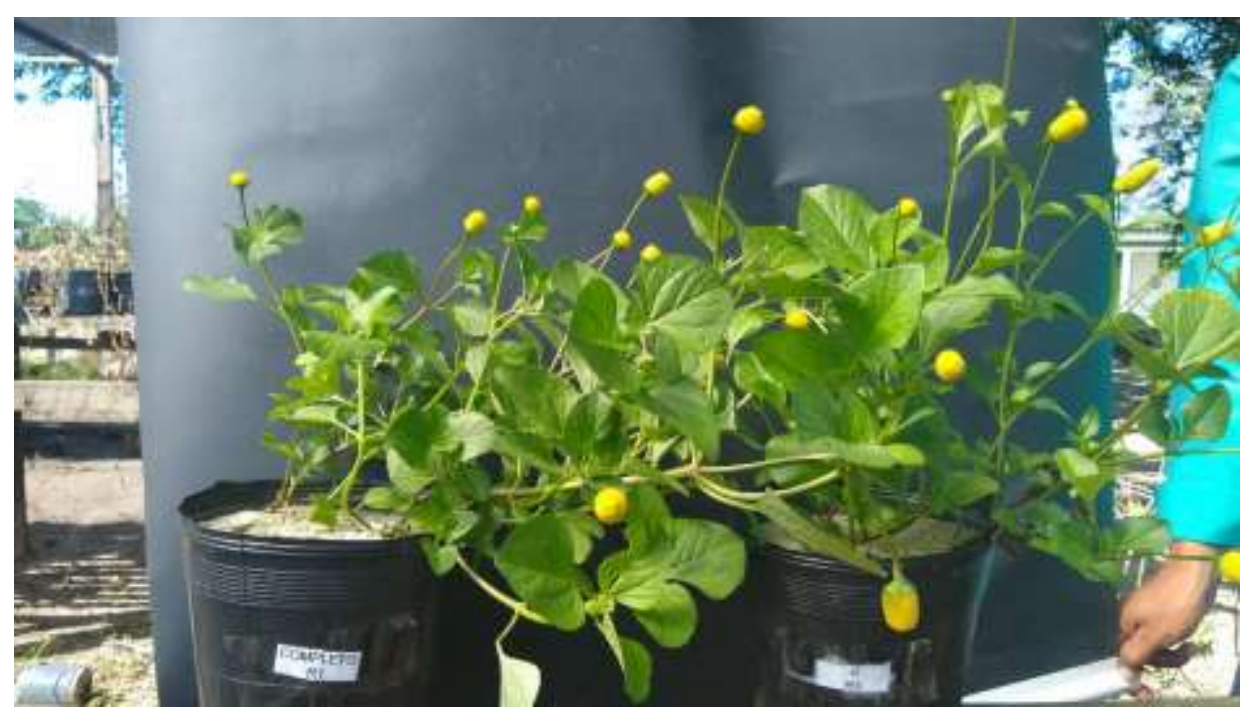

Fonte: Autores (2019)

Os sintomas de deficiência de cálcio com a omissão de nutriente deu-se pela deformação e clorose, partindo da base para o ápice das folhas mais novas como apresentado na figura 4. Resultados semelhantes foram encontrados por Costa (2017) ao realizar omissão de nutrientes na cultura da melancia, além disso, foi verificado um aspecto gelatinoso. Esse sintoma inicial de deficiência é característico, pois o pectato de cálcio é responsável pela composição da parede celular, além de atuar na maioria dos processos de crescimento, desenvolvimento, manutenção e reprodução (TAIZ \& ZEIGER, 2009). Os sintomas foram observados principalmente nas folhas mais novas, visto que esse elemento é pouco móvel na planta, não sendo redistribuído com facilidade no vegetal quando há carência no sistema radicular, como consequência de sua baixa mobilidade na planta, os sintomas de deficiências aparecem primeiramente nas folhas mais novas (EPSTEIN \& BLOOM, 2006). 
Figura 4 - Vaso a esquerda da imagem com Solução Completa; vaso à direita omissão de Cálcio (Ca)

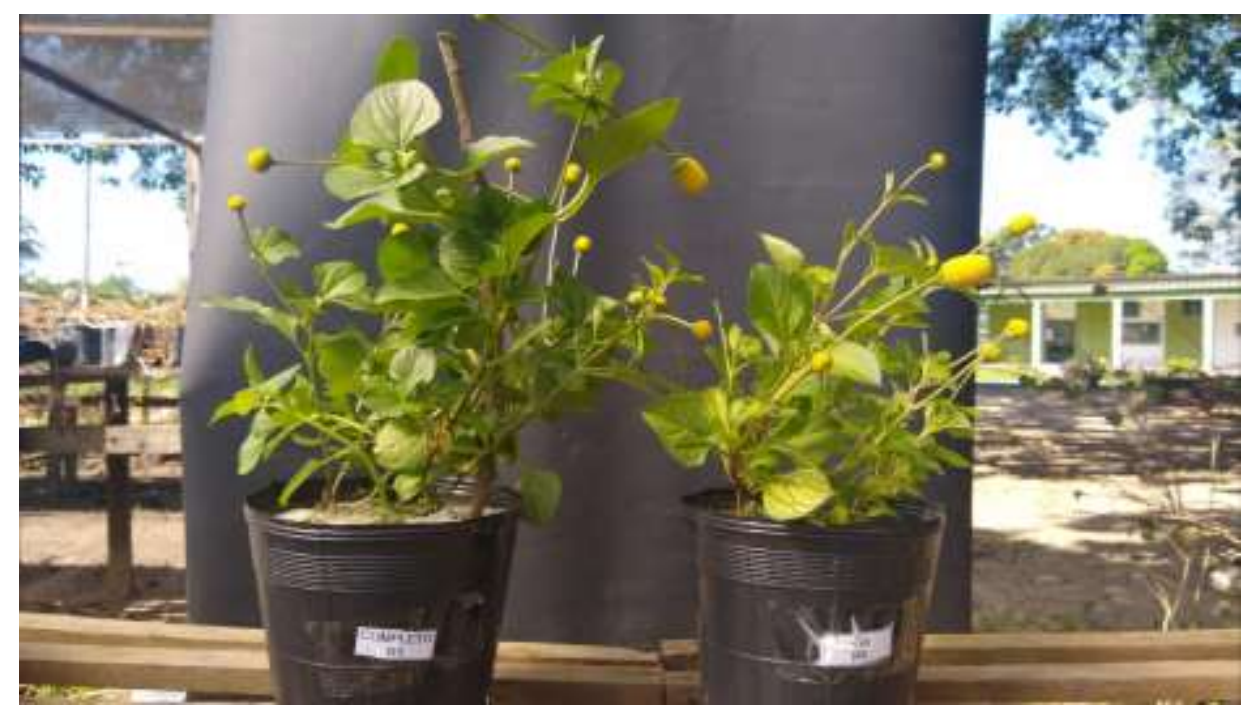

Fonte: Autores (2019)

Com relação à omissão de magnésio, foi verificado primeiramente clorose nas folhas mais velhas como é possível verificar na figura 5, e com o avanço dos sintomas foi observado clorose entre as nervuras, o sintoma está relacionado com a decomposição da clorofila. Hermans \& Verbruggen (2005) verificaram que a deficiência de Mg causou forte redução na concentração de clorofila. Esse sintoma de carência de magnésio é característico nas folhas mais velhas, pois o magnésio é um elemento altamente móvel quanto a sua redistribuição para outras regiões de crescimento (HAWKESFORD et al., 2012). Com o avanço dos sintomas, verificou-se pequenos pontos necróticos no limbo foliar. Segundo Verbruggen e Hermans (2013), além de ser constituinte da molécula de clorofila, o Magnésio é um importante cofator enzimático (ALVES PEÇANHA, 2019). Sua ausência, assim como o potássio, leva ao acúmulo de oxigênio que resulta em clorose e formação de putrescina, que quando acumulada resulta na morte celular (BASSO E SMITH,1974). 
Figura 5 - Vaso a esquerda da imagem com Solução Completa; vaso à direita omissão de Magnésio $(\mathrm{Mg})$

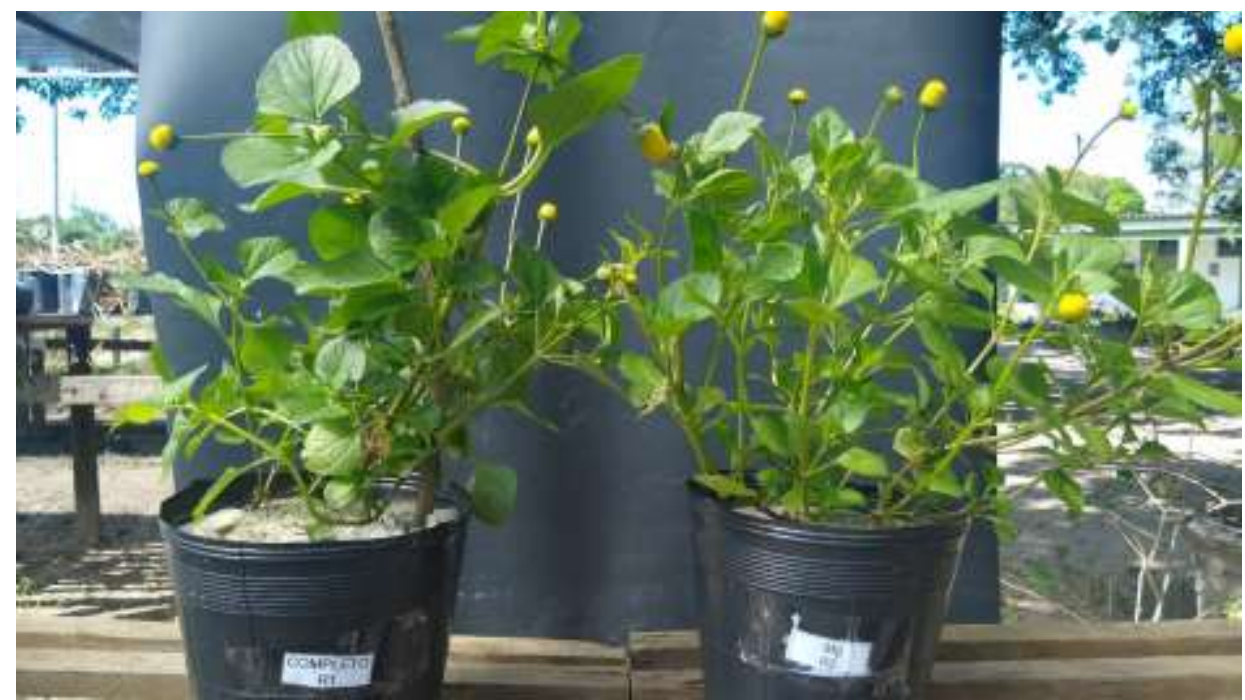

Fonte: Autores (2019)

$\mathrm{Na}$ omissão de enxofre foram observados sintomas de coloração verde clara nas folhas mais novas como mostra a figura 6, pois o enxofre tem baixa mobilidade na redistribuição para regiões em franco crescimento da planta. De acordo com Duarte (2017) o enxofre desempenha funções vitais para as plantas, dentre elas composição de aminoácidos, além de estar de forma indireta na formação da molécula de clorofila, e sua carência pode comprometer a fotossíntese. Resultados diferentes foram encontrados por Souza (2017) ao realizar omissão de nutrientes na cultura do algodão e não encontraram sintomatologia de deficiência de enxofre.

Figura 6 - Vaso a esquerda da imagem com Solução Completa; vaso à direita omissão de Enxofre (S)

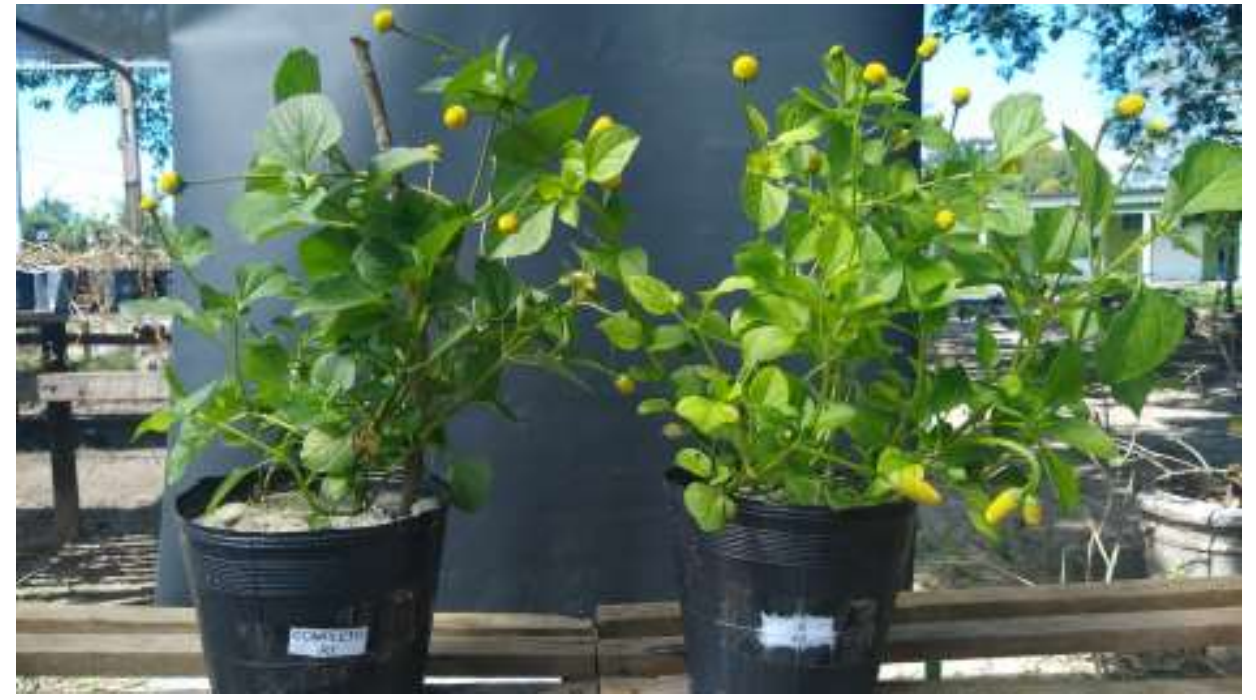

Fonte: Autores (2019) 
Com a omissão de Ferro, foi observada primeiramente uma coloração verde clara e posterior clorose internerval nas folhas mais novas, formando um reticulado fino como se pode visualizar na figura 7 , isso ocorre por que o ferro tem baixa mobilidade no floema, não ocorrendo à redistribuição do ferro para as folhas mais novas como consequência a lâmina foliar amarelece, enquanto as nervuras podem ficar verdes por algum tempo.

Figura 7- Vaso a esquerda da imagem com Solução Completa; vaso à direita omissão de Enxofre (S)

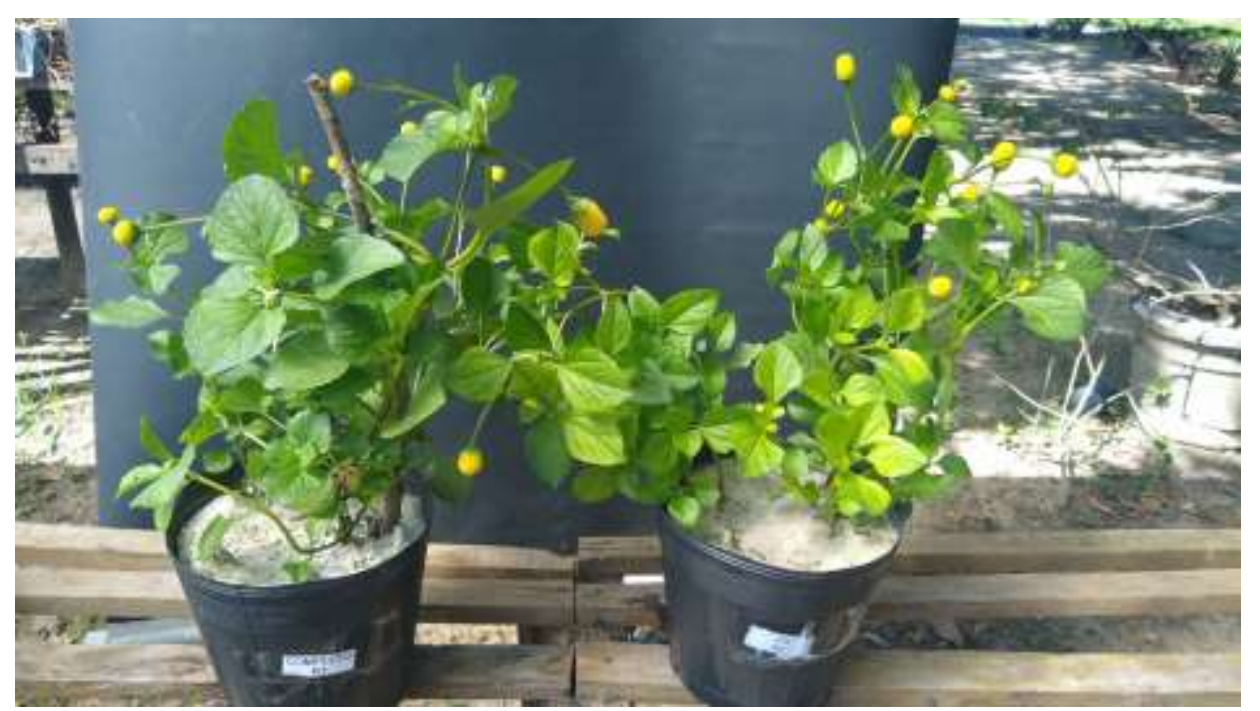

Fonte: Autores (2019)

Segundo Raij et al. (1991), o transporte de ferro se dá na corrente transpiratória e, no exsudado do xilema, o ferro aparece largamente como quelado de ácido cítrico. Resultados semelhantes foram encontrados por De Souza (2015) ao observar sintomas clorore internerval, seguidas de reticulado fino na cultura da amoreira. 
Tabela 3 - Resumo da análise de variância (ANOVA) entre os nutrientes e a Matéria Seca da parte Aérea (MS Aérea) e da Matéria Seca da Raiz (MS - Raiz) e seus respectivos Coeficientes de Variação ( CV\%). Médias seguidas de letras distintas nas colunas diferem entre si pelo teste de Tukey a 5\% de probabilidade.

\begin{tabular}{lllll}
\hline Nutriente & MS - Aérea & CV\% & MS - Raiz & CV\% \\
\hline Nitrogênio & $4,438 \mathrm{ab}$ & 17,9 & $2,28 \mathrm{a}$ & 50,21 \\
Fósforo & $8,772 \mathrm{bc}$ & 40,98 & $1,954 \mathrm{a}$ & 37,02 \\
Potássio & $4,10 \mathrm{a}$ & 20,33 & $1,516 \mathrm{a}$ & 41,3 \\
Cálcio & $8,22 \mathrm{ab}$ & 17,23 & $2,044 \mathrm{a}$ & 35,9 \\
Magnésio & $12,54 \mathrm{~cd}$ & 16,51 & $1,53 \mathrm{a}$ & 43,33 \\
Enxofre & $15,238 \mathrm{~d}$ & 20,4 & $1,638 \mathrm{a}$ & 35,76 \\
Ferro & $16,486 \mathrm{~d}$ & 10,89 & $1,584 \mathrm{a}$ & 41,63 \\
Completo & $15,83 \mathrm{~d}$ & 17,98 & $1,592 \mathrm{a}$ & 65,56 \\
\hline
\end{tabular}

Fonte: Autores (2019)

De acordo com a tabela 1 , os tratamentos diferiram entre si em nível $5 \%$ de significância com relação à matéria seca da parte aérea, enquanto as matérias secas das raízes não diferiram. Essa diferença na matéria seca está relacionada às diferentes fontes de nutrientes e suas respectivas omissões, pois a planta demanda quantidades diferentes de nutrientes para o seu desenvolvimento. A partir dessa diferença na matéria seca da parte aérea é possível constatar que houve limitação no crescimento ocasionado pelas omissões.

Gráfico 1 - Efeitos das omissões de nutrientes sobre a Matéria Seca Aérea

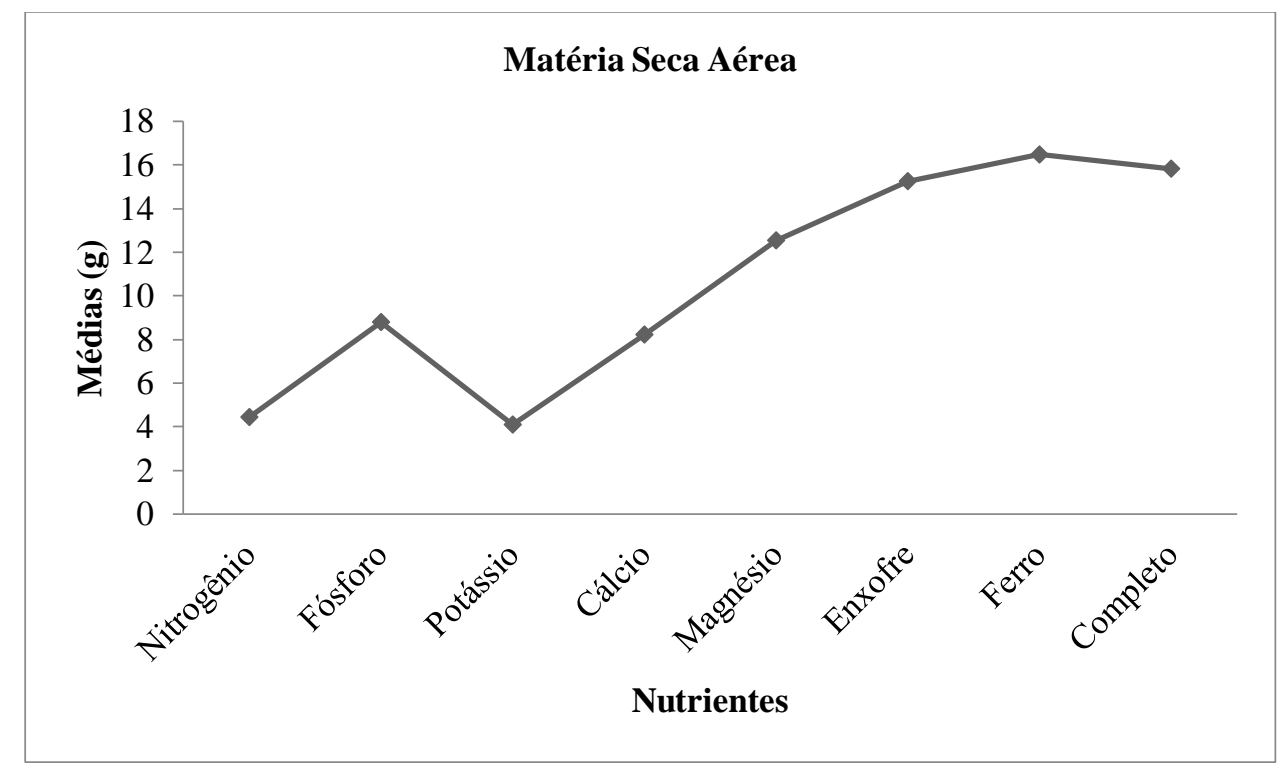

Fonte: Autores (2019)

De acordo com o gráfico 1 , os menores valores para matéria seca da parte aérea foram encontrados no tratamento com omissão de Potássio. Essa redução da matéria seca ocorreu 
devido ao aumento progressivo dos sintomas de deficiência nutricional e a sucessiva necrose nas folhas mais velhas, que é caracterizada pelo acúmulo de putrescina, poliamina que quando em altas concentrações causa sérios desequilíbrios a nível celular em tecidos vegetais (PATHAK et al., 2014).

De acordo com Hawkesford et al. (2012), o K na planta desempenha funções imprescindíveis para ativação enzimática, síntese de carboidratos, ácidos nucleicos e proteínas, osmoregulação das células e fotossíntese. Costa (2017) realizando omissão de nutrientes na cultura da melancia observou sintomas semelhantes de clorose e sucessiva necrose do tecido celular vegetal. A omissão de nitrogênio foi o segundo elemento que mais comprometeu o crescimento da planta. Segundo Carmello (1999) o nitrogênio é o macronutriente que está relacionado com os mais importantes processos bioquímicos e fisiológicos que ocorrem na planta, tais como fotossíntese, respiração, desenvolvimento e atividade das raízes, absorção iônica de outros nutrientes, crescimento e diferenciação celular.

Esses resultados corroboram com os encontrados por Souza (2017) ao avaliar omissão de nutrientes em algodoeiro e verificaram decréscimo na matéria seca. O Cálcio foi o terceiro nutriente mais limitante ao crescimento na cultua. A falta de cálcio reduz drasticamente o crescimento, pois esse nutriente faz parte da síntese da parede celular, em particular na lamela média (TAIZ \& ZEIGER, 2004).

$\mathrm{Na}$ omissão de fósforo foi verificada uma grande redução do crescimento quando comparada ao completo, sendo o terceiro nutriente mais limitante para a cultura. Por ser um macronutriente é requerido em altas quantidades, e na sua falta compromete o desenvolvimento. Além disso, ele tem papel importante na nutrição das plantas desempenhando função estrutural, no processo de armazenamento de energia (MALAVOLTA et al., 1989). Na omissão de magnésio e de enxofre não houve diferença significativa quando comparada ao tratamento com solução completa. Resultados semelhantes foram encontrados Prado \& Leal (2006), e verificaram que não houve diferença significativa na omissão de magnésio e enxofre quando comparadas ao tratamento completo. Já com relação à omissão de ferro, observaram-se valores maiores do que os encontrados para matéria seca da solução completa, isso pode ser explicado pelo fato das plantas terem recibo solução nutritiva completa até a formação das inflorescências, antes pode ter acontecido acúmulo de ferro, e como esse elemento geralmente é requerido em pequenas quantidades, e a planta não sofreu 
reduções. Com isso, fica evidente que o ferro e o enxofre, não representação um nutriente limitante a cultura nessas condições avaliadas.

Gráfico 2 - Efeitos da omissão na Matéria Seca das Raízes

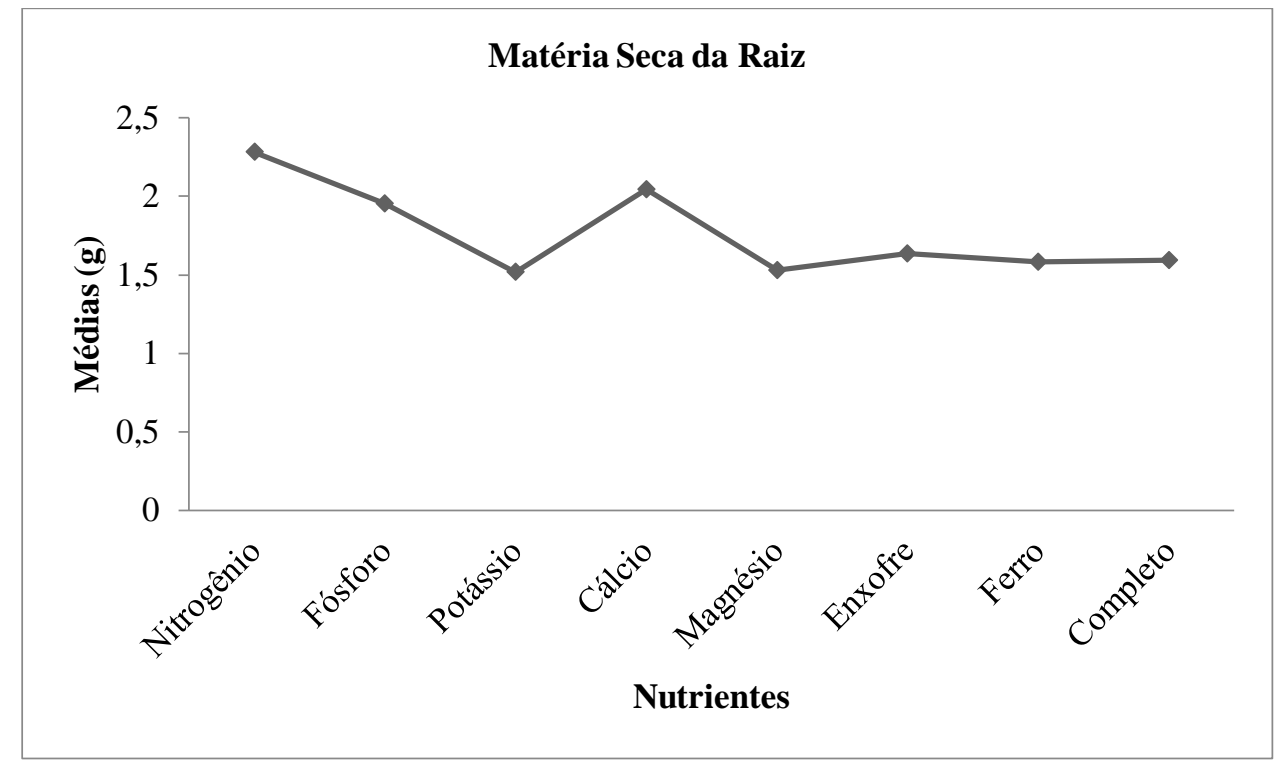

Fonte: Autores (2019)

De acordo com o gráfico 2, não foi verificada diferença significativa entre os tratamentos. Além disso, foi verificado que os tratamentos com omissões de nutrientes apresentaram maiores valores para matéria seca das raízes. Pode ser explicado pelo fato dessas omissões forçarem a planta a buscar mais nutrientes fazendo com que ela aumentasse o seu tamanho. Resultados diferentes foram obtidos por Souza (2017) ao realizar omissões com a cultura do algodoeiro e verificaram $90 \%$ de redução da matéria seca das raízes nas omissões de N,P e K.

\section{Conclusões}

Verificou-se que a cultura expressou os sintomas de deficiência e decréscimo na matéria seca da parte aérea, mostrando que a omissão é uma boa ferramenta na verificação das deficiências.

Observou-se ainda, que o potássio foi o nutriente que mais limitou o crescimento da cultura.

Em ordem decrescente os tratamentos que mais limitaram o crescimento da cultura foram: Potássio $>$ Nitrogênio $>$ Cálcio $>$ Fósforo $>$ Magnésio $>$ Enxofre $>$ Ferro. 


\section{Referências}

ALVES PEÇANHA, Diego et al. Characterization of deficiency symptoms and mineral nutrient content in Acmella oleracea cultivated under macronutrient and boron omissions. Journal of Plant Nutrition, v. 42, n. 8, p. 879-890, 2019.

BARBOSA, Alan F. et al. Spilanthol: occurrence, extraction, chemistry and biological activities. Revista Brasileira de Farmacognosia, v. 26, n. 1, p. 128-133, 2016.

BARROSO, Deborah Guerra et al. Diagnóstico de deficiências de macronutrientes em mudas de teca. Revista árvore, v. 29, n. 5, p. 671-679, 2005.

BASSO, Luiz C.; SMITH, Terence A. Effect of mineral deficiency on amine formation in higher plants. Phytochemistry, v. 13, n. 6, p. 875-883, 1974.

CARMONA, V. V.; COSTA, L. C.; CECÍlIO FILHO, A. B. Symptoms of nutrient deficiencies on cucumbers. International Journal of Plant \& Soil Science, v. 8, n. 6, p. 1-11, 2015.

CARMELLO, Q. A. C. Curso de nutrição/fertirrigação na irrigação localizada. Piracicaba: Departamento de Solos e Nutrição de Plantas, 1999.

CHAMINADE, R. Recherches sur fertilité et la fertilisation des sols dans les regions tropicales. Agronomie, Paris, v. 27, n. 9, p. 8891-8904, 1972.

COSTA, Leonardo Correia et al. Sintomas de deficiências de macronutrientes em melancieira. Comunicata Scientiae, v. 8, n. 1, p. 80-92, 2017.

DE GUSMÃO, Mônica Trindade Abreu; DE GUSMÃO, Sérgio Antonio Lopes (Ed.). Jambu da Amazônia: Acmella oleracea,(L.) RK Jansen: características gerais, cultivo convencional, orgânico e hidropônico. UFRA, Universidade Federal Rural da Amazônia, 2013.

DE SOUZA, Filipe Bittencourt Machado et al. Sintomas visuais de deficiência de macronutrientes, boro e ferro e composição mineral de amoreira-preta. Pesquisa Agropecuária Tropical, v. 45, n. 2, p. 241-248, 2015.

DUARTE, Amanda. FONTES E DOSES DE ENXOFRE NO RENDIMENTO DE GRÃOS DE SOJA. 2017.

DUBEY, Suchita et al. Phytochemistry, pharmacology and toxicology of Spilanthes acmella: a review. Advances in pharmacological sciences, v. 2013, 2013.

EPSTEIN, E., Bloom, A.J. (2004) Nutrição mineral de plantas: princípios e perspectivas. 2 ed. Editora Planta: Londrina, 403p.

EPSTEIN, E; Bloom, A. Nutrição mineral de plantas. 2.ed. Londrina: Planta, v.1, 2006. 416p. 
FERNANDES, M. S. Nutrição Mineral de Plantas. Sociedade Brasileira de Ciência do Solo, p. 432, 2006.

HAAG, H. P. Manual de adubação. São Paulo: Associação Nacional para Difusão de Adubos-ANDA, 1971.

Hawkesford, M., Horst, W., KIchey T., Lambers, H., Schjoerring, J., Moller, I.S., White, P. 2012. Functions of macronutrients In: Marschner, P. (ed). Mineral Nutrition of Higher Plants. Academic Press, London, p. 135-189.

HERMANS, Christian et al. Magnesium deficiency in sugar beets alters sugar partitioning and phloem loading in young mature leaves. Planta, v. 220, n. 4, p. 541-549, 2005.

HOAGLAND, Dennis Robert et al. The water-culture method for growing plants without soil. Circular. California agricultural experiment station, v. 347, n. 2nd edit, 1950.

HOMMA, A. K. O. Extrativismo vegetal na Amazônia: história, ecologia, economia e domesticação. In: HOMMA, A. K. O.; SANCHES, R. S.; MENEZES, A. J. E. A.; GUSMÃO, S. A. L. (ed.). Etnocultivo do jambu para abastecimento da cidade de Belém, no Estado do Pará. Brasília, DF: Embrapa, 2014. p. 329-343.

MALAVOLTA, Eurípedes et al. Elementos de nutrição mineral de plantas. São Paulo: Agronômica Ceres, 1980.

MALAVOLTA, Eurípides; KLIEMANN, Huberto J. Desordens nutricionais no cerrado. 1985.

MALAVOLTA, E.; MALAVOLTA, M. L. Diagnose foliar: princípios e aplicações. BULL, LT, ROSOLEM, CA Interpretação de análise química de solo e planta para fins de adubação. Botucatu, Fundação de Estudos e Pesquisas Agrícolas e Florestais, Faculdade de Ciências Agronômicas, Universidade Estadual Paulista, p. 227-308, 1989.

MALAVOLTA, Eurípedes; VITTI, Godofredo César; OLIVEIRA, Sebastião Alberto de. Avaliação do estado nutricional das plantas: princípios e aplicações. 1997.

MENDES, H. C. Nutrição do algodoeiro. I. Sintomas de deficiências minerais em plantas vegetando em soluções nutritivas. Bragantia, v. 18, n. 3, p. 467-481, 1959.

PATHAK, Malabika Roy; TEIXEIRA DA SILVA, Jaime A.; WANI, Shabir H. Polyamines in response to abiotic stress tolerance through transgenic approaches. GM crops $\&$ food, v. 5, n. 2, p. 87-96, 2014.

PRACHAYASITTIKUL, Veda et al. High therapeutic potential of Spilanthes acmella: a review. EXCLI journal, v. 12, p. 291, 2013

PRADO, R. M., LEAL. R. M. Desordens nutricionais por deficiência em girassol var. catissol-01. Pesquisa Agropecuária Tropical, p. 193, 2006. 
RAIJ, B. V. et al. Fertilidade do solo e adubação. São Paulo: Agronômica Ceres, 1991.

RODRIGUES, D. S. et al. Influência da adubação com nitrogênio e fósforo na produção de Jambu, Acmella oleracea (L) RK Jansen. Revista Brasileira de Plantas Medicinais, p. 71-76, 2014.SILVA, Ana Zelia et al. Sintomas de deficiências de macronutrientes em pimentão. 2013.

SANCHES, P. A. Suelos de los trópicos: características y manejo. San José: IICA, 1981. 660 p.

SILVA, E. B.; GONÇALVES, N. P.; PINHO, P. J. Limitações nutricionais para crescimento de mudas de umbuzeiro em Latossolo Vermelho distrófico no norte de Minas. Acta Scientiarum Agronomy, Maringá, v. 27, n. 1, p. 55-59, 2005.

SILVA, W. G.; TUCCI, C. A.; HARA, F. A. S.; SANTOS, R. A. C. Efeito de micronutrientes sobre o crescimento de mudas de mogno (Swietenia macrophylla King) em Latossolo Amarelo. Acta Amazonica, Manaus, v. 37, n. 3, p. 371-376, 2007.

SILVA, Ana Zelia et al. Sintomas de deficiências de macronutrientes em pimentão. 2013.

SOUZA, P. A.; VENTURIN, N.; MACEDO, R. L. G. Adubação mineral do Ipê-Roxo. Ciência Florestal, Santa Maria, v. 16, n. 3, p. 261-270, 2006.

SOUZA, Felipe Guedes de et al. Diagnose por subtração de macronutrientes em algodoeiro BRS Topázio. 2017.

TAIZ, L., ZEIGER, E. Fisiologia vegetal, p. 719, 2004.

TAIZ, L.; ZEIGER, E. Fisiologia vegetal. 4.ed. Porto Alegre: Artmed, 2009. 722p.

TAIZ, Lincoln; ZEIGER, Eduardo; MAFFEI, Massimo. Fisiologia vegetale. Piccin, 2013.

VENTURIN, Nelson et al. ADUBAÇÃO MINERAL DA CANDEIA (Eremanthus erythropappus DC.) McLeish. Floresta, v. 35, n. 2, 2005.

VERBRUGGEN, Nathalie; HERMANS, Christian. Physiological and molecular responses to magnesium nutritional imbalance in plants. Plant and soil, v. 368, n. 1-2, p. 87-99, 2013.

VIÉGAS, Ismael de Jesus Matos et al. EFEITOS DAS OMISSIÇÕES DE MACRONUTRIENTES E BORO NA SINTOMATOLOGIA E CRESCIMENTO EM PLANTAS DE AÇAIZEIRO (Euterpe oleracea Mart.). Revista de Ciências Agrárias Amazonian Journal of Agricultural and Environmental Sciences, v. 50, n. 1, p. 129-142, 2008.

YOST, Matt A. et al. Potassium management during the rotation from alfalfa to corn. Agronomy journal, v. 103, n. 6, p. 1785-1793, 2011. 